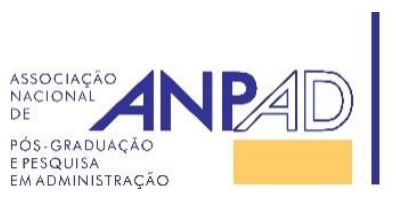
Disponível em
http://www.anpad.org.br/rac
RAC, Rio de Janeiro, v. 20, n. 2, art. 2, pp. 154-174, Mar./Abr. 2016
http://dx.doi.org/10.1590/1982-7849rac2016150019
(cc) EY

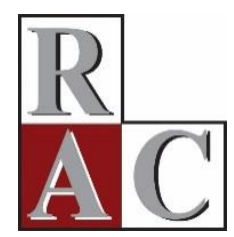

\title{
Efeitos da Música ao Vivo e Mecanizada em Ambientes de Varejo Supermercadista
}

Effects of Live and Mechanized Music in Retail Environments

Marconi Freitas da Costa ${ }^{1}$ Salomão Alencar de Farias ${ }^{2}$

Universidade de São Paulo ${ }^{1}$ Universidade Federal de Pernambuco ${ }^{2}$

Artigo recebido em 02.02.2015. Última versão recebida em 22.04.2015. Aprovado em 19.05.2015. Publicado online em 01.12.2015. 


\title{
Resumo
}

Este artigo teve o objetivo de analisar o efeito da música ao vivo, comparada à música mecanizada, além da ausência de música, sobre o comportamento do consumidor em ambientes supermercadistas. Foram realizados dois experimentos de campo, em dois supermercados. Os resultados dos dois estudos mostram evidências empíricas de que a música ao vivo, comparada à música mecanizada (e à sua ausência), é capaz de influenciar os aspectos afetivos dos consumidores, levando os mesmos a avaliarem o ambiente de varejo de forma mais positiva, a apresentarem intenções de comportamento mais favoráveis, como recomendar a empresa para amigos, fazer comentários positivos, entre outros. Além disso, a música ao vivo mostra-se mais influente sobre o comportamento do consumidor quando estes estão menos concentrados com a atividade de compra.

Palavras-chave: atmosfera de varejo; música ao vivo; música mecanizada.

\begin{abstract}
This article aimed to analyze the effect of live music, compared to mechanized music, and the absence of music on consumer behavior in supermarket environments. Two field experiments were conducted in two supermarkets. The results of both studies show empirical evidence that live music, as compared to mechanized music (and the absence of music), is able to influence consumers' affective aspects, leading them to assess the retail environment more positively, to show more favorable behavioral intentions, such as recommending the company to friends and making positive comments, among others. In addition, live music seems to be more influential on consumer behavior when they are less concentrated on buying activity.
\end{abstract}

Key words: retail atmosphere; live music; mechanized music. 


\section{Introdução}

Os primeiros estudos que abordaram os impactos do ambiente sobre o comportamento dos indivíduos datam dos anos 60 (Cox, 1964; Smith \& Curnow, 1966), entretanto foi Kotler (1973) quem propôs o termo atmosfera de varejo para designar o planejamento consciente do ambiente com o intuito de criar certos efeitos nos compradores.

Do estudo inicial de Kotler (1973), percebe-se na literatura que o interesse pela temática tem evoluído e alguns estudos foram feitos destacando a relevância da atmosfera como um fator de influência no processo de decisão de compra (e.g., Bitner, 1992; Donovan \& Rossiter, 1982; N. Bailey \& Areni, 2006). Os resultados desses estudos convergem para a proposição de se trabalhar de forma planejada um conjunto de elementos que podem influenciar as reações afetivas, cognitivas ou físicas dos consumidores.

Dada a importância dos estímulos que podem ser trabalhados dentro do ambiente de varejo, considerou-se importante, nesse estudo, investigar especificamente a atmosfera física de supermercado, porque também se verifica a proeminência desse segmento no Brasil. Nos últimos anos, de acordo com a Associação Brasileira de Supermercados (ABRAS, 2013), o varejo no Brasil vem se transformando, tornando-se mais competitivo com a chegada de varejistas internacionais e com a aquisição de redes nacionais por grupos estrangeiros.

Um dos casos que pode ilustrar essa transformação foi a compra do Bompreço pelo Walmart, maior rede varejista do mundo. Além disso, os grupos de grande abrangência, como o Extra e o Carrefour, competem fortemente no setor supermercadista com estratégias de precificação, localização, entre outras. Este setor tem se tornado mais competitivo e percebe-se o retorno da utilização de unidades supermercadistas menores, em bairros específicos, com oferta de serviços e ambientes diferenciados.

Considerando a relevância do ambiente de varejo supermercadista e os elementos que podem ser trabalhados dentro dele, este estudo visa direcionar os esforços para um dos estímulos ambientais: a música. Para Milliman (1986), dos vários estímulos do ambiente aos quais um cliente pode ser exposto em um cenário de varejo, a música tem sido identificada como um dos mais facilmente manipuláveis.

As pesquisas que documentam os efeitos da música sobre o comportamento do consumidor são consistentes e enfatizam a preferência dos indivíduos por alguns aspectos específicos como o ritmo, o tom, o volume e o compasso (e.g. Kellaris \& Rice, 1993; Milliman, 1986). Entretanto, um estudo que ainda não foi explorado pelos pesquisadores é sobre o efeito da música ao vivo, comparada à música mecanizada, no comportamento do indivíduo. A música ao vivo tem uma peculiaridade no que diz respeito à performance inerente à sua produção. A atividade de produzir a música ao vivo é capaz de envolver as pessoas que estão apenas ouvindo (ou assistindo) a performance de um músico (Iazzetta, 1997).

Bartók (1976) faz uma analogia com a produção de frutas para destacar a principal diferença entre a música mecanizada e a música ao vivo. De acordo com esse autor, a primeira é como se fosse a fruta enlatada e, a segunda, a fruta fresca; uma não contém vitamina, a outra contém. Além disso, a música mecanizada é o resultado de uma produção em massa, enquanto que a música ao vivo é trabalhada artesanalmente (Bartók, 1976).

Os estudos que foram feitos (Götell, Brown, \& Ekman, 2009; L. M. Bailey, 1983; Sherratt, Thorton, \& Hatton, 2004; Vleuten, Visser, \& Meewesen, 2012) para avaliar os impactos da música ao vivo sobre os indivíduos, comparando com a música mecanizada, estão na área da saúde. Essas pesquisas procuraram analisar os benefícios da performance ao vivo sobre o bem-estar dos pacientes com diferentes níveis de demência e com câncer.

O papel da performance na apresentação da música ao vivo é um ponto determinante na diferenciação com a música mecanizada, porque alguns ouvintes acabam criando uma conexão com o 
cantor, participando de forma indireta da produção sonora, ao reconstruir internamente as sequências de notas produzidas pelos instrumentos musicais, bem como mentalizando a estrutura formal da composição (Iazzetta, 1997). Essa conexão do ouvinte (consumidor) com o músico torna-se uma experiência de alto valor, devido à capacidade da música ao vivo de seduzir e mobilizar os consumidores (Herschmann, 2008).

É possível perceber, pelo menos no Brasil, que o uso da música ao vivo é muito comum em estabelecimentos com apelo hedônico, como bares e restaurantes. O estudo de Kaltcheva e Weitz (2006) trouxe evidências empíricas de que o estímulo da música pode proporcionar uma experiência prazerosa ou não, dependendo do tipo de varejo, se é um varejo voltado para o consumo hedônico ou utilitário, sendo este último considerado como de experiência não prazerosa pelos consumidores.

Considera-se que os ambientes supermercadistas, em sua atividade fim, não são projetados para experiências hedônicas do consumidor (Nguyen, Nguyen, \& Barret, 2007; Yim, Yoo, Sauer, \& Seo, 2014), principalmente os supermercados que estão competindo no mercado com a estratégia de preços baixos. Estes diminuem os investimentos no requinte do ambiente (e.g., climatização, gôndolas sofisticadas, piso com material de primeira linha, etc.), para diminuir os custos, obtendo, com isso, margem para baixar os preços dos produtos.

Com base no contex to apresentado nos parágrafos anteriores, o presente estudo procurou estender e contribuir com a literatura sobre os efeitos da música em ambientes de varejo ao preencher uma lacuna teórica identificada, sobre a comparação dos efeitos da música ao vivo e da música mecanizada em ambientes de supermercado. A premissa inicial da pesquisa é de que a relação da performance da música ao vivo sobre o indivíduo traz efeitos mais positivos, quando comparada à música mecanizada (e à ausência de música), sobre as emoções do consumidor, as intenções de comportamento e a avaliação da qualidade do ambiente.

Além disso, o estudo pretendeu avaliar mais especificamente o papel mediador das emoções positivas e negativas entre os estímulos das músicas (ao vivo, mecanizada e ausência) com as intenções de comportamento e a avaliação do ambiente, porque se considera que o ambiente de supermercado é voltado para o consumo utilitário (Nguyen et al., 2007; Yim et al., 2014), podendo estimular, de certa forma, experiências positivas ou negativas.

Por fim, verificou-se também, como uma extensão da análise do primeiro experimento que foi realizado neste estudo, o papel moderador da concentração do cliente no momento da compra sobre a relação da música com o comportamento do consumidor. Esta última análise tem por base o estudo de N. Bailey e Areni (2006), em que o cliente é mais afetado pela música quando não está envolvido mentalmente em alguma atividade dentro do ambiente.

Este artigo é composto por esta introdução, por uma seção sobre a revisão da literatura - onde são apresentados os conceitos que guiaram esta pesquisa, os resultados dos principais estudos encontrados sobre a temática em análise, bem como as hipóteses da pesquisa -, por um tópico sobre os procedimentos metodológicos, seguido por um tópico com a apresentação dos dois experimentos realizados, e finalizando com a discussão geral dos achados.

\section{Revisão da Literatura}

\section{A música ao vivo e mecanizada}

Os estudos que foram encontrados na literatura sobre a música ao vivo e a mecanizada trataram, eminentemente, da comparação entre ambas em relação ao mercado da música, mais especificamente dos avanços tecnológicos favorecendo a música mecanizada em detrimento das apresentações ao vivo (Baumol \& Bowen, 1966; Frith, 2013; Herschmann, 2008). Vários estudos retratam a evolução histórica 
da música, destacando a transição da música artesanal para o uso da tecnologia (e.g., Frederickson, 1989; Leichtentritt, 1934; Sousa, 1906; Taylor, 2007).

De acordo com Herschmann (2008), a música, ao vivo e/ou mecanizada, é onipresente no cotidiano da sociedade contemporânea. Para esse autor, a música mecanizada vem sendo veiculada em diferentes meios analógicos e digitais, sendo comercializada não apenas como produto final, mas também como suporte para oferta de produtos e serviços aos consumidores.

O termo música mecanizada, em seu sentido mais estrito, aplica-se à música produzida sem a assistência direta de um tocador/intérprete, ou, também, a música transmitida por um dispositivo (rádio, computador, etc.) durante um longo intervalo (Frederickson, 1989). O som mecanizado domina a indústria da música, porém, de acordo com Herschmann (2008), a música ao vivo vem recuperando o espaço perdido, e esta retomada está relacionada com os consumidores que buscam nas performances dos concertos vivenciar experiências e sensações diferentes do cotidiano.

Segundo Iazzetta (1997), a música ao vivo tem a capacidade, por meio de sua performance, de envolver o ouvinte em um contexto não apenas formado de instrumentos musicais e sequências de notas, mas também de um universo gestual que a acompanha. Para esse autor, as presenças do músico e do instrumento no momento da performance representam algo por si mesmas. A realidade física, biológica e social dessa presença empresta à performance musical algo de materialidade, porque o corpo se expressa ao produzir música por meio do gesto (Iazzetta, 1997).

Os resultados do estudo de L. M. Bailey (1983) dão suporte à teoria de que a música ao vivo tem mais efeitos sobre os indivíduos do que a música mecanizada, ao apresentar as mudanças emocionais e físicas dos pacientes hospitalizados com câncer. Ainda sobre a pesquisa, a apresentação da música ao vivo foi caracterizada pela presença de um ser humano (corpo e voz) como o originador do som musical, o que pode ter sido significativo para os pacientes ao diminuir a sensação de isolamento e, assim, afetando positivamente o humor.

Este efeito da música ao vivo sobre pacientes hospitalizados ainda encontra respaldos nos estudos de Vleuten, Visser e Meewesen (2012), Sherratt, Thorton e Hatton (2004) e Götell, Brown e Ekman (2009). Contudo, esse estudo ainda não foi feito em ambientes de varejo, para verificar o impacto sobre o comportamento do consumidor. Os consumidores, em um contexto de ambiente de supermercado, têm perspectivas discrepantes dos pacientes que estão hospitalizados, e por isso verifica-se a importância de avaliar se a música ao vivo conseguiria efeitos semelhantes das pesquisas na área da saúde. Os principais estudos que foram feitos sobre os efeitos da música no ambiente de varejo estão sintetizados nos tópicos seguintes, começando pela relação dos aspectos afetivos e a música ambiente.

\section{Aspectos afetivos e a música no ambiente}

A música dentro do ambiente pode reduzir, mesmo relativamente, emoções extremas, como ansiedade intensa (Garlin \& Owen, 2006; Lee, Henderson, \& Shum, 2004). No entanto, o ambiente interno percebido não leva diretamente as pessoas a comportarem-se de determinadas maneiras; percepções do ambiente conduzem a certas emoções, crenças e sensações fisiológicas que, por sua vez, influenciam comportamentos (Bitner, 1992). Muitos estudos exploram estas relações intermediárias, dos efeitos particulares de música-humor (Andersson, Kristensson, Wästlund, \& Gustafsson, 2012; Bruner, 1990; McGoldrick \& Pieros, 1998).

Para esta pesquisa, mais especificamente, foram empregados os conceitos dos afetos positivos e negativos. Watson, Clark e Tellegen (1988) propuseram a escala Positive and Negative Affect Schedule (PANAS), que procura mensurar as dimensões dos afetos positivos e negativos. Para estes autores, os afetos positivos e negativos têm consistentemente emergido como duas dominantes e apresentam relativamente independentes dimensões, embora os termos afetos positivos e negativos possam sugerir que são fatores opostos, isto é, correlacionados negativamente. 
Para o desenvolvimento da escala, Watson et al. (1988) pesquisaram em vários estudos uma ampla e representativa amostra de termos sobre afetos. Depois de identificados claramente os aspectos afetivos básicos, os autores focaram em criar um instrumento para mensurá-los de forma simples e econômica, em outras palavras, direcionaram os esforços na construção de uma escala concisa. Esse objetivo de síntese pode ter sido a causa de algumas críticas que são tecidas sobre a escala PANAS, em que alguns pesquisadores (e.g. Cohen, Pham, \& Andrade, 2008; Larsen, McGraw, \& Cacioppo, 2001) apontam, entre outras críticas, a falta de outros termos para ambas as dimensões, positivas e negativas.

A dimensão positiva da escala PANAS é composta por dez itens: entusiasmado, interessado, determinado, ativo, inspirado, alerta, empolgado, forte, orgulhoso e atento. Já a dimensão negativa é composta pelos seguintes dez itens: assustado, angustiado, chateado, frustrado, ansioso, nervoso, envergonhado, culpado, irritado e hostil. Os autores Cohen, Pham e Andrade (2008) chamam a atenção dos pesquisadores pelos itens que estão faltando na escala. Para o afeto positivo, no estado de baixa e moderada ativação, estão faltando itens, por exemplo, satisfeito, positivo e sereno, e no estado de alta ativação tem itens que predominam, tais como, ativo, alerta, atento e empolgado.

Da mesma forma, para o afeto negativo, estão faltando itens no estado de baixa e moderada ativação, por exemplo, infeliz, negativo, deprimido e triste, enquanto predominam itens no estado de alta ativação (e.g., angustiado, nervoso e chateado). A despeito das críticas construtivas que a escala PANAS recebeu, este instrumento tem sido relevante para a compreensão dos afetos positivos e negativos.

Com base na discussão sobre a efetividade dos efeitos da música sobre os aspectos afetivos em ambientes de varejo, e também nos conceitos sobre a música ao vivo apresentados anteriormente, foram elaboradas hipóteses de pesquisas para o experimento 1 e 2 . Vale ressaltar que a composição das hipóteses para o experimento 1 se refere apenas à comparação entre a música ao vivo e a sua ausência sobre as variáveis dependentes. Para o experimento 2, que é o principal objetivo deste estudo, há a inclusão do grupo com a música mecanizada para comparação com os demais grupos (música ao vivo e ausência de música). Assim, com um caráter meramente ilustrativo, optou-se por apresentar as hipóteses no formato mais completo, para otimizar a apresentação das hipóteses dos dois experimentos.

$\mathbf{H}_{1}$ : A presença de música ao vivo, comparada com a música mecanizada (e com a ausência de música), tem um efeito mais positivo sobre os aspectos afetivos do consumidor.

Além disso, considerando a relevância do papel mediador dos aspectos afetivos (positivos e negativos) sobre o comportamento do consumidor, no experimento 1 e 2 foi feita a avaliação dessa medição por meio da hipótese $\mathbf{H}_{\mathbf{1}}$ : Os aspectos afetivos positivos (e negativos) têm um papel mediador na relação da música ao vivo sobre as intenções de comportamento e a avaliação da qualidade do ambiente. No tópico seguinte são apresentados os conceitos e estudos sobre a música e as intenções de comportamento.

\section{A música e as intenções de comportamento}

Os autores Mowen e Minor (2003) definem o construto das intenções de comportamento como a expectativa que o consumidor tem sobre a forma como este se comportará em relação à aquisição e descarte de produtos e serviços. O consumidor pode ter a intenção de procurar por informações, de contar para outras pessoas sua experiência com a compra, de comprar um produto ou serviço e ainda de descartar um produto de determinada maneira.

Evidências baseadas nas pesquisas e nas práticas sugerem que as respostas afetivas e cognitivas dos clientes em relação às experiências no interior da loja influenciam as intenções ou a probabilidade de comportamentos que impactam diretamente os retornos financeiros de uma organização (Garlin \& Owen, 2006). Jain e Bagdare (2011) especificam esses retornos financeiros como: valor das vendas, repetição das compras, itens comprados, quantidade comprada e margem bruta. 
As publicações revisadas por esta pesquisa destacam as crenças implícitas dos gestores na capacidade da música ambiente em facilitar retornos superiores aos negócios (Areni, 2003; DeNora \& Belcher, 2000). Vida, Obadia e Kunz (2007) relataram que a preferência (gosto) da música pelos compradores no ambiente natural de varejo e a música percebida ajustam-se positivamente com a imagem da empresa afetando o tempo de compras, o qual, por sua vez, influencia indiretamente as despesas dos consumidores.

A música está presente em muitos ambientes dos consumidores com o propósito eminente de influenciar a percepção do tempo (Bruner, 1990; Kellaris \& Rice, 1993; Milliman, 1986). Modelos cognitivos de tempo subjetivo sugerem que a duração de um intervalo de tempo preenchido com música deve ser percebida de maneira diferente do que um intervalo de tempo vazio; no entanto, nem todas as músicas irão produzir o mesmo efeito (Kellaris \& Kent, 1993).

Donovan e Rossiter (1982) fizeram uma pesquisa para avaliar os impactos da atmosfera de varejo sobre as intenções de comportamento, mais especificamente em relação ao valor maior de compra do cliente e em relação à permanência no ambiente de varejo. O estudo desses autores tomou por base os conceitos elaborados por Mehrabian e Russell (1974), tendo estes últimos autores postulado que toda resposta para um ambiente pode ser considerada como comportamento de aproximação ou de afastamento. Os resultados do estudo de Donovan e Rossiter (1982), embora não tenha sido uma pesquisa experimental, trazem evidências de que as respostas aos estímulos do ambiente aumentam os gastos dos indivíduos além dos originalmente esperados por eles, bem como aumentam o tempo de permanência na loja.

Com base nos argumentos descritos nos parágrafos anteriores, foram elaboradas as seguintes hipóteses para o experimento 1 e experimento 2, seguindo a mesma orientação para apresentar as hipóteses dos dois experimentos, conforme foi definido anteriormente. $\mathbf{H}_{\mathbf{2}}$ : A presença de música ao vivo, comparada à música mecanizada (e à sua ausência), relaciona-se com o valor maior de compra do cliente. Além da hipótese $\mathbf{H}_{\mathbf{2 b}}$ : A presença de música ao vivo, comparada à música mecanizada (e à sua ausência), relaciona-se com o aumento no tempo de permanência dos clientes na loja.

Os estudos de Spangenberg, Crowley e Henderson (1996) e Matilla e Wirtz (2001) fornecem suporte a outros três itens que compõem o construto de intenções de comportamento em ambientes de varejo: retorno ao estabelecimento, indicação da loja e fazer comentários positivos sobre o ambiente. Os autores Spangenberg et al. (1996) encontraram evidências que um ambiente de varejo com um aroma não ofensivo, comparado com sua ausência, pode aumentar a intenção dos consumidores de visitar novamente a loja. A cor também é outro estímulo do ambiente de varejo que também contribui para a intenção de retorno à loja (Crowley, 1993).

Com isso, acredita-se que a música ao vivo seja também um estímulo capaz de impactar a intenção de retorno de forma semelhante ao aroma e a cor do ambiente. Para isso, foi elaborada a hipótese $\mathbf{H}_{\mathbf{2} \mathbf{c}}$ : A presença de música ao vivo, comparada à música mecanizada (e à sua ausência), relaciona-se de maneira mais positiva com a intenção de retorno à loja.

As intenções de indicar a loja para amigos e de fazer comentários positivos sobre o ambiente de varejo foram mensuradas diretamente nos estudos de Matilla e Wirtz (2001), ao avaliarem os efeitos do aroma sobre estes dois tipos de comportamento. Além disso, a pesquisa de Spangenberg et al. (1996) também trouxe contribuições no que concerne à influência significativa do ambiente de varejo sobre a propensão dos indivíduos em fazer comentários positivos em relação à loja.

Segundo Jain e Bagdare (2011), após fazerem um levantamento de várias pesquisas referentes aos impactos da música ambiente sobre as intenções de comportamento dos consumidores, existe uma tendência dos indivíduos de recomendar ou indicar a loja para amigos e conhecidos quando o ambiente tem a presença de música. Já o estudo de Garlin e Owen (2006), que também compila os principais resultados de outras pesquisas, dá suporte à tendência dos consumidores de fazer comentários positivos sobre a loja quando há presença de música no ambiente de varejo. 
Diante das evidências encontradas nas pesquisas sobre efeitos dos estímulos ambientais, seja na forma de aroma ou música, sobre as intenções de comportamento de indicar a loja e de fazer comentários positivos, foram elaboradas mais duas hipóteses: A hipótese $\mathbf{H}_{\mathbf{2 d}}$ : A presença de música ao vivo, comparada à música mecanizada (e à sua ausência), relaciona-se de maneira mais positiva com a intenção de indicar a loja para amigos e conhecidos. E a hipótese $\mathbf{H}_{2 \mathrm{e}}$ : A presença de música ao vivo, comparada à música mecanizada (e à sua ausência), relaciona-se de maneira mais positiva com a intenção de fazer comentários positivos sobre a loja.

\section{Estímulos da música e avaliação da qualidade do ambiente}

O construto sobre a avaliação da qualidade do ambiente foi explorado no estudo de Spangenberg et al. (1996) em relação aos estímulos do aroma dentro do ambiente de varejo. Para estes autores, as pistas ou sinais do ambiente de natureza estimulante, como o aroma, bem como a cor ou a música, devem majorar a própria natureza instigante do ambiente, elevando, assim, a avaliação do quão aprazível e interessante ele é. De acordo com alguns estudos (Baker, Levy, \& Grewall, 1992; Chebat, Chebat, \& Vaillant, 2001; Demoulin, 2011; Spangenberg, Grohmann, \& Sprott, 2005), pequenas alterações no ambiente, tais como a inclusão da música ambiente, aumentam a percepção de um lugar agradável e original, criando, dessa forma, uma avaliação superior pelo indivíduo.

Fischer (1974), em sua pesquisa, avaliou a qualidade estética do ambiente para grupos com pessoas semelhantes e dessemelhantes. De acordo com os resultados da pesquisa, o grupo em que as pessoas tinham a percepção de serem semelhantes, por meio de manipulação, avaliaram melhor a qualidade estética do ambiente, em comparação ao grupo com pessoas dessemelhantes.

Para avaliar a qualidade do ambiente, Fischer (1974) desenvolveu uma escala de diferencial semântico com quatorze itens (i.e., atraente - não atraente, relaxante - tenso, confortável desconfortável, animado - desanimado, aberto - fechado, colorido - desbotado, positivo - negativo, estimulante - tedioso, bom - ruim, com vida - sem vida, claro - sombrio, motivante - desmotivante, interessante - desinteressante, agradável - desagradável).

Neste estudo, espera-se que o estímulo da música ao vivo melhore a avaliação da qualidade estética do ambiente. Para isso, foi elaborada a seguinte hipótese $\mathbf{H}_{3}$ : A presença de música ao vivo, comparada à música mecanizada (e à sua ausência), traz influência mais positiva para a avaliação da qualidade estética do ambiente. No tópico seguinte são descritos os procedimentos metodológicos empregados nesta pesquisa.

\section{Aspectos Metodológicos}

Para realização do presente estudo foram feitas duas pesquisas de campo com caráter quaseexperimental (between-subjects design). Os dados foram coletados com a aplicação de questionários, em dois supermercados, para a realização dos dois experimentos. Os respondentes foram abordados aleatoriamente dentro do supermercado. Nesse momento, era avisado ao entrevistado que a participação era voluntária e que a entrevista durava em torno de 8 minutos. Aproximadamente, a cada 5 clientes abordados, 4 participavam. Dois entrevistadores participaram da coleta, os mesmos foram treinados pelos pesquisadores desta pesquisa para a execução da tarefa.

Uma descrição dos pontos comuns dos dois supermercados é que ambos são supermercados convencionais, de acordo com a definição de supermercado de Pride e Ferrell (2010), sendo ambientes de autosserviço que ofertam uma linha completa de produtos alimentícios e alguns produtos nãoalimentícios. O primeiro, onde foi feito o estudo 1, pertence a um grupo estrangeiro, e o segundo, a um grupo local. Ambos os supermercados estão localizados na cidade de Recife. Os supermercados foram contatados sem conhecimento prévio dos pesquisadores em relação aos gestores. O primeiro foi 
escolhido porque já tinha a música ao vivo, o segundo porque tem a mesma característica do primeiro, embora não tivesse já a prática da música ao vivo.

O repertório utilizado nos dois experimentos, tanto na música ao vivo quanto na música mecanizada, foi composto por canções nacionais, que fazem parte da música popular brasileira (MPB). As músicas são provenientes dos seguintes artistas: Djavan, Seu Jorge, Ana Carolina, Maria Gadú, Gilberto Gil, Zélia Duncan, Ana Cañas, Marisa Monte, Cássia Eller, entre outros.

As fontes das escalas utilizadas nos questionários foram: para os aspectos afetivos positivos e negativos, Watson et al. (1988); para as intenções de comportamento, recomendar, fazer comentários, gastar tempo extra, gastar mais dinheiro e retornar, Spangenberg et al. (1996), Matilla e Wirtz (2001), Mehrabian e Russel (1974) e Donovan e Rossiter (1982); e para a avaliação da qualidade estética do ambiente, Fischer (1974) e Spangenberg et al. (1996).

O questionário também passou por um pré-teste com uma amostra de 20 respondentes, com o objetivo de aprimorar o instrumento de coleta, mas o resultado do pré-teste mostrou que não seria necessário fazer ajustes. As escalas foram traduzidas por meio da técnica de tradução reversa (back translation).

\section{Experimentos e Resultados}

\section{Estudo 1}

No estudo 1, por meio de experimento de um fator (single fator), o objetivo foi mensurar o efeito da música ao vivo ( $v s$. ausência de música) em um supermercado, sobre alguns aspectos do comportamento do consumidor, quais sejam: aspectos afetivos (positivos e negativos), intenções de comportamento e avaliação da qualidade estética do ambiente. A análise também foi estendida por meio do teste da ANOVA Two Way, com a variável da música ao vivo e as variáveis demográficas do gênero e da idade. Além disso, foi feita a análise do papel mediador dos aspectos afetivos (positivos e negativos).

\section{Participantes}

Com base em estudos anteriores (Andersson et al., 2012; Herrington \& Capella, 1994; North, Hargreaves, \& McKendrick, 1999; Yalch \& Spangenberg, 2000), foi definida uma amostra mínima de 120 respondentes por grupo, para que restasse uma quantidade em torno de 100 respondentes, considerando que em toda pesquisa de campo alguns questionários são excluídos por apresentarem falhas em seu preenchimento. Com isso, foram aplicados 240 questionários, sendo 120 do grupo de controle (ausência de música) e 120 do grupo de experimento (música ao vivo). A amostra final válida para os grupos controle e experimento foi 113 e 102, respectivamente, após eliminação dos questionários com erros de preenchimento.

\section{Procedimentos e medidas}

O supermercado do experimento 1 está presente em diferentes localidades do país, pertencente a um grupo estrangeiro do setor. O estabelecimento oferece música ao vivo nos finais de semana. A música é tocada por um cantor local com o uso de um violão e um microfone ligado a uma caixa amplificadora, localizado na entrada principal do supermercado (com o som da música sendo projetado para dentro do ambiente), durante o final de semana, das 10 às 16 horas.

Os respondentes foram abordados no interior do supermercado, sem o oferecimento de incentivo para participação na pesquisa, no momento em que estavam na fila, aguardando para efetuar o pagamento das compras. A coleta foi realizada entre os dias 14 e 17 de fevereiro de 2013, sendo dois 
dias (quinta e sexta) para o grupo de controle e dois dias (sábado e domingo) para o grupo do experimento.

Em relação às escalas de medidas do Afeto Positivo $(\alpha=0,960)$, do Afeto Negativo $(\alpha=0,933)$ e da Avaliação da Qualidade Estética do Ambiente $(\alpha=0,976)$, estas tiveram os itens, já apresentados na Revisão da Literatura, transformados em índice, por meio da Summated Scale.

As perguntas utilizadas para o construto das Intenções de Comportamento foram: Recomendaria para um amigo que fizesse compras nesta loja, Estou propenso a fazer comentários positivos sobre esta loja, Eu usei tempo extra para explorar a loja, Eu acabei gastando mais dinheiro do que originalmente planejado, estes itens foram mensurados em uma escala de concordância com sete pontos $(1=$ discordo totalmente, $7=$ concordo totalmente $)$. A pergunta que mensurou a intenção de comportamento de retornar ao estabelecimento foi: Assumindo que você fosse comprar esse(s) tipo(s) de produto futuramente, que possibilidade haveria de o(a) senhor(a) voltar a esta loja?; este item foi mensurado em uma escala de intensidade com 7 pontos $(1=$ baixa, 7 = alta $)$.

\section{Resultados}

O teste $t$ de student de comparação entre médias mostrou uma diferença significativa entre os grupos da música ao vivo $(\mathrm{n}=113)$ e da ausência de música $(\mathrm{n}=102)$ sobre os aspectos positivos $\left(M_{\text {música_vivo }}=5,53, M_{\text {ausência }}=5,05 ; t(213)=4,294, p<0,01\right)$, sobre os aspectos negativos $\left(M_{\text {música_vivo }}=\right.$ $\left.2,72, M_{\text {ausência }}=2,49 ; t(213)=2,352, p<0,05\right)$, sobre a intenção de recomendar para os amigos $\left(M_{\text {música_vivo }}=5,14, M_{\text {ausência }}=4,79 ; t(213)=3,318, p<0,01\right)$, sobre a intenção de fazer os comentários positivos do supermercado $\left(M_{\text {música_vivo }}=5,32, M_{\text {ausência }}=4,68 ; t(213)=4,440, p<0,01\right)$, sobre o comportamento de gastar mais tempo para explorar o supermercado $\left(M_{\text {música_vivo }}=4,66, M_{\text {ausência }}=3,59\right.$; $t(213)=5,418, p<0,01)$, sobre o comportamento de gastar mais dinheiro $\left(M_{\text {música_vivo }}=4,64, M_{\text {ausência }}=\right.$ $3,66 ; t(213)=4,966, p<0,01)$, sobre a intenção de retornar ao estabelecimento ( $M_{\text {música_vivo }}=5,21$, $\left.M_{\text {ausência }}=4,84 ; t(213)=2,910, p<0,05\right)$, e, por fim, sobre a avaliação da qualidade estética do ambiente $\left(M_{\text {música_vivo }}=4,94, M_{\text {ausência }}=4,68 ; t(213)=2,214, p<0,05\right)$.

Também foram feitos testes, com o propósito de estender a análise, para comparação dos grupos da música ao vivo e com ausência de música utilizando as variáveis demográficas gênero e idade, para verificar se o perfil do respondente traria algum efeito de interação. Os resultados do teste da ANOVA Two Way mostram um efeito principal da música ao vivo $(M=5,53, \mathrm{DP}=0,766)$, comparada à ausência de música $(M=5,05, \mathrm{DP}=0,856)$, sobre os aspectos negativos $(F(1,211)=17,842, p<0,05)$. Mas não houve efeito principal do gênero (Feminino: $\mathrm{n}=116$; Masculino: $\mathrm{n}=99 ; F(1,211)=0,990, p>0,05$ ), nem da interação das duas variáveis categóricas $(F(1,211)=0,041, p>0,05)$. Também teve efeito significativo a música ao vivo $(M=2,72, \mathrm{DP}=0,820)$, comparada à ausência de música $(M=2,49, \mathrm{DP}$ $=0,633)$, sobre os aspectos negativos $(F(1,211)=5,532, p<0,05)$. Entretanto, não houve efeito principal do gênero $(F(1,211)=1,484, p>0,05)$, bem como da interação $(F(1,211)=0,875, p>0,05)$.

Para o construto das intenções de comportamento, com a análise da ANOVA Two Way, a música ao vivo apresentou efeito significativo para todas as variáveis dependentes: recomendar para um amigo que fizesse compra neste supermercado $\left(M_{\text {música_vivo }}=5,17, M_{\text {ausência }}=4,79 ; F(1,211)=12,233, p<0,05\right)$, fazer comentários positivos sobre o supermercado $\left(M_{\text {música } \_ \text {vivo }}=5,32, M_{\text {ausência }}=4,68 ; F(1,211)=21,633\right.$, $p<0,05)$, usar tempo extra para explorar o supermercado $\left(M_{\text {música } \_ \text {vivo }}=4,66, M_{\text {ausência }}=3,59 ; F(1,211)\right.$ $=30,857, p<0,05)$, gastar mais dinheiro do que o originalmente planejado $\left(M_{\text {música } \_ \text {vivo }}=4,64, M_{\text {ausência }}\right.$ $=3,66 ; F(1,211)=24,645, p<0,05)$ e retornar ao estabelecimento $\left(M_{\text {música_vivo }}=5,21, M_{\text {ausência }}=4,84\right.$; $F(1,211)=9,546, p<0,05)$.

Contudo, não houve efeito principal do gênero para estas variáveis. Sobre a interação das variáveis da música ao vivo (vs. ausência de música) e do gênero, foram encontradas interações para todas as variáveis das intenções de comportamento (Figura 1), exceto para a variável com o gasto maior do originalmente planejado. 


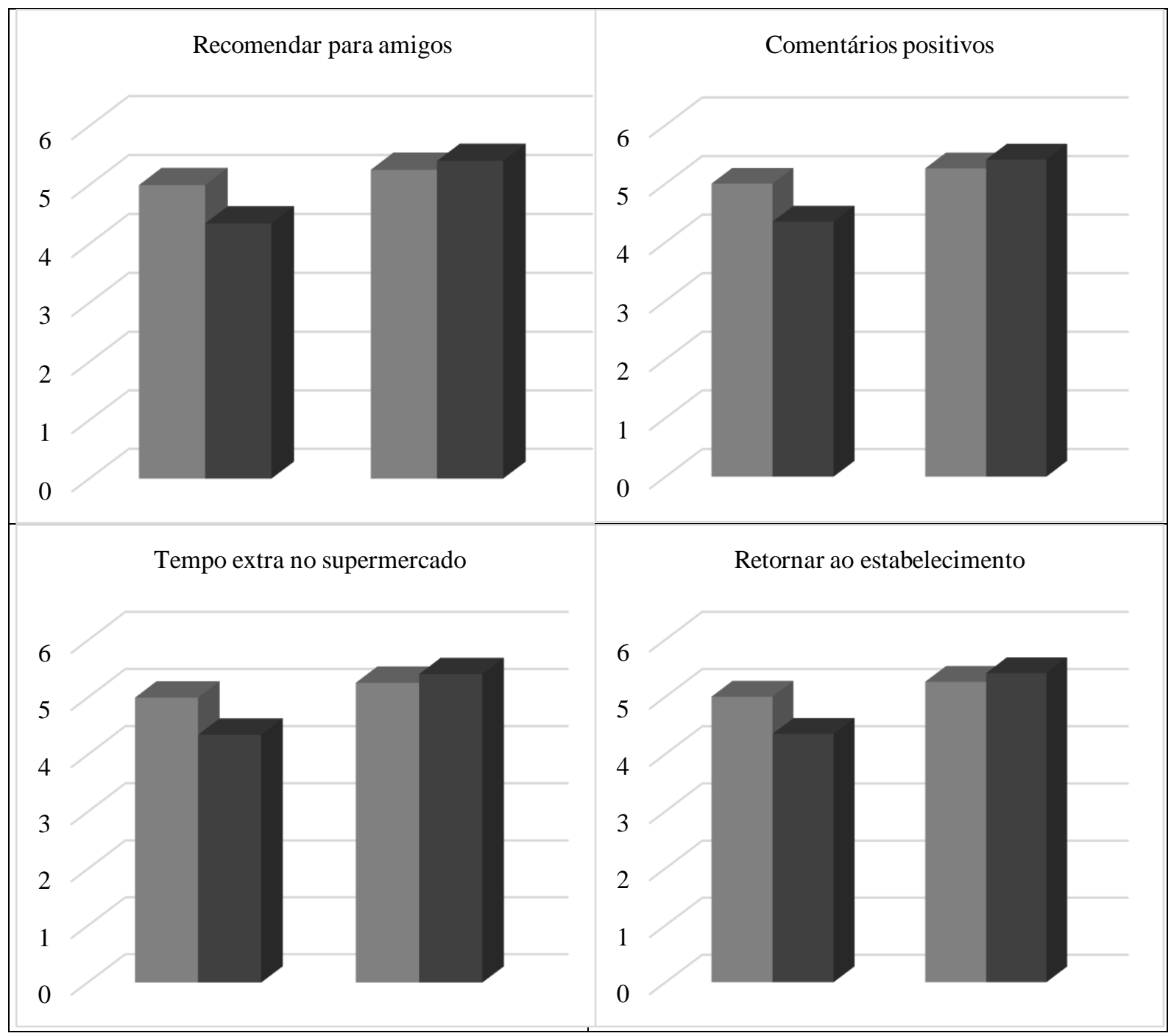

Figura 1. Interação das Variáveis da Música ao Vivo (vs. Ausência) e Gênero

As duas colunas da esquerda = Grupo com Ausência de Música; As duas colunas da direita = Grupo com Música aoVivo (Em cada quadrante). A coluna de cor cinza claro $=$ Feminno; A colunca de cor cinza escuro $=$ Maculino .

A música ao vivo $(F(1,211)=4,859, p<0,05)$ e o gênero $(F(1,211)=4,228, p<0,05)$ tiveram efeito principal sobre a avaliação da qualidade estética do ambiente, porém a interação das variáveis não teve efeito significativo $(F(1,211)=1,363, p>0,05)$.

Além do gênero, também foi avaliada a interação com a variável idade (18 a 25 anos: $n=49 ; 26$ a 35 anos: $\mathrm{n}=54 ; 36$ a 45 anos: $\mathrm{n}=43 ; 46$ a 55: $\mathrm{n}=36$; Acima de 55: $\mathrm{n}=33$ ). O teste da ANOVA Two Way mostrou um efeito principal da música ao vivo $(F(1,205)=15,694, p<0,01)$ sobre os aspectos positivos, mas não teve efeito principal da idade $(F(4,205)=1,769, p>0,05)$, e também não há efeito significativo da interação entre as variáveis $(F(4,205)=1,812, p>0,05)$. Para a variável dos aspectos negativos, a música ao vivo teve um efeito principal significativo $(F(1,205)=8,204, p<0,05)$, porém a idade não apresentou o mesmo resultado $(F(4,205)=2,215, p>0,05)$, bem como a interação das variáveis não foi significativa $(F(4,205)=1,201, p>0,05)$.

Para as intenções de comportamento, a música ao vivo apresentou um efeito principal sobre a intenção de recomendar para amigos $(F(1,205)=9,586, p<0,05)$, assim como a variável idade $(F(4$, $205)=5,632, p<0,01)$, e também foi encontrada uma interação significativa dessas duas variáveis $(F(4$, $205)=2,634, p<0,05)$. Resultado igual em relação à significância do efeito principal de ambas as variáveis, bem como da interação entre elas, foi encontrado para mais duas variáveis das intenções, a variável de fazer comentários positivos e a de gastar tempo para explorar o ambiente. Com isso, o teste 
Post-hoc de Scheffé mostrou que o subgrupo com as pessoas de idade entre 46 a 55 anos diferem dos subgrupos 26 a 35 e 36 a 45 anos.

Para as variáveis das intenções de comportamento de gastar mais dinheiro do que o originalmente planejado e retornar ao estabelecimento, foram encontrados efeitos principais das duas variáveis categóricas (música ao vivo; idade). Contudo, não teve efeito significativo da interação entre elas $(F(4$, $205)=1,747, p>0,05 ; F(4,205)=1,382, p>0,05$, respectivamente) sobre as duas variáveis dependentes. O teste Post-hoc de Scheffé mostrou que para a variável de gastar mais dinheiro, os subgrupos de 36 a 45 e 46 a 55 anos diferem, e para a variável de retornar ao estabelecimento o subgrupo de 46 a 55 anos difere dos subgrupos 18 a 25,26 a 35 e 36 a 45 anos.

Em seguida, verificou-se que a música ao vivo teve efeito principal sobre a avaliação da qualidade estética do ambiente $(F(1,205)=3,897 p=0,05)$. Este efeito principal sobre a variável dependente também foi encontrado para a variável idade $(F(4,205)=4,336, p<0,01)$. Além disso, a interação das variáveis da música ao vivo e da ausência de música com a variável idade teve um resultado estatisticamente significativo sobre a avaliação do ambiente $(F(4,205)=2,482, p<0,05)$. E o teste Post-hoc de Scheffé mostrou que o subgrupo de 46 a 55 anos difere dos subgrupos 18 a 25, 26 a 35 e 36 a 45 anos.

Por fim, avaliou-se o efeito mediador dos aspectos afetivos (positivos e negativos) na relação entre a música ao vivo e as intenções de comportamento, bem como com a avaliação da qualidade do ambiente. Para facilitar a interpretação, foi criado um índice (Summated Scale) do construto das intenções de comportamento $(\alpha=0,910)$. O teste da mediação foi feito pela macro PROCESS do SPSS (Hayes, 2013). O resultado do teste mostrou que há um efeito da variável da música ao vivo (vs. ausência de música), transformada em dummy, sobre as intenções de comportamento $(\beta=0,68, t(213)=5,05, p$ $<0,01)$. Entretanto, a variável do afeto positivo não teve um papel mediador nessa relação, após sua inclusão no modelo $(\beta=0,28, t(212)=2,76, p<0,01)$, e o mesmo aconteceu com a inclusão do afeto negativo $(\beta=0,81, t(212)=6,48, p<0,01)$.

O resultado do teste mostrou um efeito da música ao vivo sobre a avaliação da qualidade estética do ambiente $(\beta=0,26, t(212)=2,21, p<0,05)$, assim, para esta relação, o afeto positivo teve um papel mediador $(\beta=-0,12, t(212)=-1,50, p>0,05)$. Por outro lado, o afeto negativo não teve a mesma contribuição no modelo $(\beta=0,39, t(212)=3,78, p<0,01)$ e, com a inclusão desta última variável, a relação continuou significativa.

\section{Discussão}

Os resultados dos testes fornecem suporte para as hipóteses que foram elaboradas, as quais têm, em sua essência, a premissa de que a música ao vivo contribui efetivamente para as avaliações mais positivas do ambiente de varejo supermercadista, quando comparadas com as avaliações do mesmo ambiente sem música.

De acordo com dados desta pesquisa, os aspectos afetivos positivos são mais bem avaliados pelo grupo com música ao vivo. Os achados corroboram a pesquisa de Bruner (1990), que enfatiza que a música utilizada em atmosfera de varejo é capaz de evocar respostas afetivas e comportamentais de uma forma não aleatória nos consumidores. Talvez esta afirmação também ajude a entender o resultado de que o afeto negativo foi um pouco mais alto para o grupo com música ao vivo, comparado com a sua ausência. O resultado sugere que o ambiente com música ao vivo pode intensificar as emoções em todos os sentidos, positivos e negativos, proporcionando experiências de consumo com elevada carga emocional.

Sobre o papel mediador dos aspectos afetivos, apenas o afeto positivo mostrou relevância nesta mediação, e apenas entre a música ao vivo e a avaliação da qualidade do ambiente. Este resultado não é consistente com outros estudos (Demoulin, 2011; McGoldrick \& Pieros, 1998) que encontraram significância estatística dos afetos dos consumidores nas avaliações dos ambientes de varejo de forma mais forte. 
Também foram analisadas hipóteses sobre o construto das intenções de comportamento, que procuraram analisar a relação da música com a intenção de retornar ao supermercado, a intenção de indicar para amigos e conhecidos, a intenção de fazer comentários positivos sobre o estabelecimento, a intenção de permanecer mais tempo no local e a intenção de gastar mais dinheiro. As hipóteses procuravam identificar se a música ao vivo traria avaliações mais positivas referentes às intenções descritas; todas elas foram confirmadas e estão de acordo com várias outras pesquisas. Por exemplo, Jain e Bagdare (2011) encontraram evidências referentes à influência da música na experiência de consumo cognitivo e nos níveis comportamentais, mais detidamente em relação a gastar mais tempo e dinheiro na experiência de varejo.

A relação da música ao vivo com a avaliação da qualidade estética do ambiente também foi investigada. Os resultados mostram que, de fato, o grupo experimento (música ao vivo) pontuou de forma mais favorável a avaliação do ambiente do que o grupo controle (ausência de música). Um estudo que reforça esses achados é o de Spangenberg, Grohmann e Sprott (2005), que indica os efeitos favoráveis da música ambiente nas avaliações dos consumidores e traz como exemplo uma pesquisa feita na época do Natal. Vale ressaltar que essa mesma pesquisa também apresenta a importância do cheiro e da música na avaliação da qualidade estética do ambiente do consumidor sobre a atmosfera de varejo.

Uma contribuição específica que pode ser inferida com base nos resultados é em relação ao momento em que os dados são coletados. Neste estudo 1, os questionários foram aplicados no momento que os clientes estavam na fila de espera para pagamento das compras. Isto pode ter ajudado em uma avaliação mais positiva dos respondentes, porque, segundo a pesquisa de N. Bailey e Areni (2006), a música tem influência para as pessoas que estão à toa, à espera de alguma coisa. Ainda para os mesmos autores, a música não teve quase nenhum efeito para os indivíduos que estavam concentrados em alguma atividade de memória durante a pesquisa. Com isso, talvez, se os clientes tivessem sido abordados no momento em que estavam escolhendo os produtos nas gôndolas e conferindo a lista de compras, os resultados poderiam ter sido diferentes.

A avaliação da concentração do consumidor com a atividade de compra não foi mensurada diretamente pelas pesquisas. O estudo feito em laboratório por N. Bailey e Areni (2006) avaliou o efeito da música em relação à percepção de tempo de espera, e observou-se que a música não teve quase nenhum efeito para os indivíduos que estavam concentrados em alguma atividade de memória durante a pesquisa. Com isso, foi elaborada mais uma hipótese para ser avaliada no estudo 2, além das hipóteses que já foram desenvolvidas e apresentadas na Revisão da Literatura, com a comparação da música mecanizada.

$\mathbf{H}_{4}$ : A música ao vivo, comparada à mecanizada (e com a ausência de música), tem uma influência mais positiva sobre os aspectos afetivos, as intenções de comportamento e a avaliação da qualidade do ambiente quando os consumidores estão com um baixo grau de concentração com a atividade de compra.

\section{Estudo 2}

No estudo 2, buscou-se complementar o estudo 1 por meio de um experimento fatorial 3 (música: música ao vivo $v s$. música mecanizada $v s$. ausência de música) x 2 (concentração com a compra: baixa vs. alta). Analisou-se os efeitos da música ao vivo, comparada à música mecanizada, considerando também o grau de concentração do consumidor com a atividade de compra, sobre os mesmos construtos analisados no estudo 1. A ideia foi estender o estudo anterior com a comparação da música mecanizada, além da inclusão do fator do grau de concentração com a compra, para verificar se este fator traria algum efeito moderador na relação da música ao vivo com os construtos dependentes. 


\section{Participantes}

Para o estudo 2, os respondentes foram abordados dentro de um outro supermercado. Para superar alguma limitação do estudo 1 , em que a música ao vivo só foi manipulada em dois dias de fim de semana (sábado e domingo), e a ausência de música em dois dias de semana (quinta e sexta), foi feito um calendário mais extenso em relação aos dias, para que contemplasse uma situação mais equitativa entre os grupos sobre os sete dias da semana. Assim, como foram três grupos (música ao vivo, mecanizada e ausência), a coleta aconteceu por vinte e um dias, sendo sete dias para cada grupo. A manipulação da música foi feita em dias alternados.

A coleta começou em uma segunda-feira, no dia 17 de novembro de 2014, com a manipulação da música ao vivo, seguindo no outro dia com a música mecanizada, e no dia seguinte, com a ausência de música, continuando até o dia 7 de dezembro de 2014. Dessa forma, as três condições tiveram a oportunidade de acontecer nos sete dias da semana. Foram estabelecidas 4 horas diárias para a coleta dos questionários, alternando entre manhã, tarde e noite, para os três grupos. Por dia, eram coletados 16 questionários, sendo 8 para a condição das pessoas que estavam aguardando na fila de pagamento (check out) e 8 para a condição das pessoas que estavam nos corredores do supermercado e que demonstravam alguma concentração na avaliação de produtos ou na verificação da lista de compras.

\section{Procedimentos}

O supermercado do estudo 2 foi selecionado pela disponibilidade para efetuar a manipulação da música ao vivo e música mecanizada. Para manipular a música ao vivo no ambiente do supermercado, foi utilizado o mesmo procedimento do estudo 1, inclusive com o mesmo músico e repertório. A manipulação da música ao vivo, mecanizada e ausência de música foi verificada por meio da pergunta Qual tipo de fonte de música você consegue ouvir neste ambiente? As opções de respostas foram: música ao vivo; música mecanizada (emitida por um rádio, computador, etc.); não estou ouvindo música neste ambiente; outra (especifique). Esta pergunta foi feita apenas ao final da entrevista para evitar que o respondente descobrisse o objetivo da pesquisa. Todos os grupos escolheram as opções que combinavam com a manipulação e nenhum respondente escolheu a opção outra.

Para checar a condição de baixa e alta concentração com a compra, com os consumidores que foram abordados nas duas situações, aguardando na fila para pagamento e avaliando produtos nos corredores do supermercado, foi feita a pergunta Qual seu grau de concentração com a compra?, para ser respondida em uma escala de 7 pontos $(1=$ baixa, $7=$ alta $)$. O resultado mostra uma diferença estatisticamente significativa entre os dois grupos $(t(329)=13,483, p<0,01)$, com o grupo que estava aguardando na fila tendo um grau menor de concentração $(M=3,01 ; D P=1,10)$, comparado ao grupo que estava analisando os produtos e a lista de compras nos corredores do supermercado $(M=4,73 ; D P=1,23)$.

\section{Resultados}

Uma ANOVA 3 (música: música ao vivo vs. música mecanizada vs. ausência de música) x 2 (concentração com a compra: baixa $v s$. alta) mostrou o efeito principal, bem como de interação da música ao vivo e do grau de concentração com a atividade de compra sobre os construtos dependentes. Os resultados mostraram um efeito significativo $(p<0,05)$ e fornecem suporte para todas as hipóteses em que os ambientes de varejo com música ao vivo teriam melhores avaliações nas respostas dos consumidores sobre os aspectos afetivos (positivos e negativos), as intenções de comportamento e a avaliação da qualidade estética do ambiente, quando comparado com o grupo de música mecanizada ou com ausência de música. As médias das respostas dos consumidores para os grupos com música ao vivo, mecanizada e com ausência de música, além dos grupos com alta e baixa concentração com a compra, podem ser conferidas na Tabela 1.

O resultado da interação das duas variáveis categóricas (música e concentração) foi significativo tanto para a variável do afeto positivo $(F(2,325)=18,782, p<0,01)$ quanto para a variável do afeto negativo $(F(2,325)=4,300, \mathrm{p}<0,05)$. Também foi encontrada interação significativa das variáveis 
para as intenções de recomendar $(F(2,325)=4,727, p<0,05)$, para as intenções de gastar tempo extra para explorar o ambiente $(F(2,325)=4,061, p<0,05)$ e para a intenção de retornar ao supermercado $(F(2,325)=13,015, p<0,01)$. Entretanto, não houve interação das variáveis sobre as intenções de fazer comentários positivos $(F(2,325)=1,576, p>0,05)$ e para o maior gasto de dinheiro do originalmente planejado $(F(2,325)=1,023, p>0,05)$. Por sim, foi observada uma interação significativa da música ao vivo e a concentração com a compra para o construto da avaliação da qualidade estética do ambiente.

Tabela 1

\section{Médias dos Grupos: Música e Concentração (Estudo 2)}

\begin{tabular}{lllllllllll} 
& \multicolumn{3}{c}{ Ausência da Música } & \multicolumn{3}{c}{ Música Mecanizada } & \multicolumn{4}{c}{ Música ao Vivo } \\
\cline { 2 - 11 } & CC & CC & Total & CC & CC & Total & CC & CC & Total \\
& Alta & Baixa & & Alta & Baixa & & Alta & Baixa & \\
\hline Afeto positivo & 4,79 & 4,25 & 4,51 & 4,27 & 5,05 & 4,767 & 4,81 & 5,17 & 5,02 \\
Afeto negativo & 3,50 & 3,05 & 3,27 & 2,92 & 2,79 & 2,85 & 3,14 & 2,53 & 2,79 \\
Recomendar para amigos & 4,09 & 4,31 & 4,20 & 4,33 & 4,53 & 4,43 & 4,49 & 5,33 & 4,97 \\
Comentários positivos & 4,58 & 4,55 & 4,56 & 4,35 & 4,85 & 4,61 & 4,90 & 5,24 & 5,09 \\
Tempo extra no ambiente & 4,28 & 4,69 & 4,49 & 4,06 & 4,78 & 4,43 & 4,41 & 5,51 & 5,04 \\
Gastou mais dinheiro & 4,26 & 4,47 & 4,37 & 4,50 & 5,22 & 4,87 & 4,84 & 5,36 & 5,14 \\
Retornar ao supermercado & 3,74 & 4,31 & 4,03 & 4,33 & 3,98 & 4,15 & 4,02 & 5,31 & 4,77 \\
Avaliação do ambiente & 4,28 & 4,40 & 4,34 & 4,75 & 4,65 & 4,70 & 4,88 & 5,28 & 5,11 \\
\hline
\end{tabular}

Nota. CC $=$ Concentração com a Compra. Fonte: Pesquisa de campo realizada em novembro/dezembro de 2014.

* As médias dos subgrupos apresentam diferenças com significância estatística do teste $F(p<0,05)$.

O teste de Post-hoc de Scheffé mostrou que o subgrupo da música ao vivo difere dos subgrupos da música mecanizada e da ausência de música para as variáveis do afeto positivo, intenções de comportamento (recomendar, comentários positivos, tempo extra e retornar ao estabelecimento) e avaliação da qualidade estética do ambiente. Ainda de acordo com o mesmo teste Post-hoc de Scheffé, o subgrupo da ausência de música difere dos subgrupos da música ao vivo e da música mecanizada para as variáveis com o gasto maior de dinheiro do originalmente planejado e com o afeto negativo.

Estendendo a análise, buscou-se mensurar a mediação moderada da variável aspectos afetivos (positivos e negativos) para o efeito da interação das variáveis da música (ao vivo, mecanizada, ausência) e da concentração (alta, baixa) sobre as intenções de comportamento que tiveram significância estatística na ANOVA Two Way (i.e., recomendar para amigos, tempo extra no ambiente e retornar ao estabelecimento) e também para a variável da qualidade estética do ambiente.

O teste da mediação moderada foi feito por meio da macro PROCESS do SPSS (Modelo 8; Hayes, 2013). A análise utilizou a música como variável independente (X), e esta variável foi transformada em duas dummies. A variável intenção de recomendar ao amigo (tempo extra no ambiente, retornar ao estabelecimento e avaliação do ambiente) foi a variável dependente (Y), os aspectos afetivos positivos/negativos serviram como variável mediadora (M), e a concentração com a compra foi a variável moderadora, codificada como dummy (W).

Os resultados do teste revelaram que não houve uma mediação moderada do afeto positivo, porque quando esta variável foi incluída no modelo, o efeito total $(\beta=0,485, t(327)=2,99, p<0,05)$ da interação da música $\mathrm{x}$ concentração sobre a intenção de recomendar para um amigo não foi reduzido $(\beta$ $=0,483, t(326)=2,90, p<0,05)$, em outras palavras, o efeito permaneceu com significância estatística. O mesmo aconteceu com a inclusão do afeto negativo no modelo, ou seja, o modelo continuou com significância $(\beta=0,472, t(326)=2,91, p<0,05)$. 
Para a intenção de gastar mais tempo no estabelecimento, o efeito de mediação moderada do afeto positivo $(\beta=0,35, t(326)=2,93, p<0,05)$ e negativo $(\beta=0,30, t(326)=2,40, p<0,05)$ não aconteceu, e o efeito total da interação da música e da concentração com a compra permaneceu significativo ( $\beta=$ $0,472, t(327)=2,91, p<0,05)$. Contudo, o efeito de mediação moderada aconteceu para a variável de intenção de retornar ao supermercado. O efeito total $(\beta=0,32, t(327)=2,24, p<0,05)$ da interação entre as variáveis categóricas foi reduzido ao acrescentar o afeto positivo $(\beta=0,25, t(326)=1,74, p>0,05)$ no modelo. O mesmo não aconteceu com a inclusão do afeto negativo $(\beta=0,30, t(326)=2,15, p<0,05)$, não apresentando mediação na relação das variáveis.

Por fim, na análise do papel mediador dos aspectos afetivos, foi analisada a variável de avaliação da qualidade estética do ambiente. Os resultados não mostram um efeito da interação da música (ao vivo, mecanizada, ausência) e da concentração (alta, baixa) sobre a avaliação do ambiente $(\beta=0,14$, $t(327)=1,61, p>0,05)$. Mesmo com a inclusão do afeto positivo e negativo, o modelo continuou sem mudança na significância estatística $\left(\beta_{\text {positivo }}=0,472, t(326)=2,91, p>0,05 ; \beta_{\text {negativo }}=0,14 t(326)=\right.$ $1,64, p>0,05)$.

\section{Discussão}

Os resultados comprovam o efeito da música ao vivo sobre os aspectos afetivos, tanto o positivo quanto o negativo, sobre as intenções de comportamento e sobre a avaliação da qualidade estética do ambiente, comparando com os efeitos da música mecanizada e com a ausência de música. Assim, todas as hipóteses tiveram suporte com base nos testes que foram operacionalizados.

A concentração do consumidor com a compra também teve relevância na compreensão do comportamento do consumidor, mostrando sua moderação no efeito da música ao vivo. Os consumidores que estão menos concentrados com a compra avaliaram mais positivamente o ambiente, corroborando as ideias de N. Bailey e Areni (2006), em que os consumidores que não estão focados em uma atividade mental conseguem perceber o ambiente mais favoravelmente. A interação da música ao vivo com o grau de concentração teve impacto nos afetos positivos e negativos, nas intenções de recomendar ao amigo, nos gastos com tempo extra para explorar o ambiente e no retorno ao estabelecimento. Além disso, a interação também teve influência sobre a avaliação da qualidade estética do ambiente.

Os resultados da interação sugerem que os consumidores que estão ouvindo música ao vivo no ambiente supermercadista e apenas aguardando para finalizar a compra estão com as emoções mais intensas, além de mais predisposições para terem comportamentos que irão ajudar o supermercado com os objetivos nos pontos de venda.

A mediação moderada do afeto positivo e negativo entre a interação da música ao vivo e a concentração do consumidor com a compra só aconteceu para a intenção de retornar ao estabelecimento, não ocorrendo para as intenções de recomendar para outras pessoas e para gastar mais tempo no estabelecimento. Esses resultados não estão em consonância com as pesquisas que avaliaram o papel mediador do afeto, como por exemplo, o estudo de Jain e Bagdare (2011), em que a música influencia a experiência de consumo emocional, especificamente no que diz respeito ao humor e ao sentimento na experiência de varejo. Contudo, acredita-se que a moderação da variável concentração tenha sido determinante neste baixo efeito significativo do papel mediador do afeto, conforme os resultados da mediação moderada.

\section{Discussão Geral e Conclusão}

A atmosfera do ambiente de varejo está sendo considerada cada vez mais como uma variável estratégica para as empresas. Muitos gestores estão construindo a identidade das empresas especialmente com a atmosfera de varejo feita sob medida para os clientes. As empresas tentam criar 
ambientes diferenciados com aspectos afetivos onde a música se encaixa com a arquitetura, a luz, os odores e com a identidade da própria empresa.

Diante de alguns estudos revisados nesta pesquisa, que datam de três décadas atrás, até os dias atuais, percebe-se que o interesse pelo entendimento dos efeitos da música sobre o comportamento do consumidor é algo que ainda suscita curiosidade nos pesquisadores. Os estudos continuam sendo feitos e sempre adicionando novos achados ou corroborando ideias já defendidas.

O objetivo principal deste artigo foi analisar a relação da música ao vivo, comparada à música mecanizada (e com a ausência de música), com os aspectos afetivos, as intenções de comportamento e as avaliações do consumidor no ambiente de varejo supermercadista. Os resultados apontam para a importância da música ao vivo em ambientes supermercadistas, porque os grupos que tiveram a manipulação da música ao vivo apresentaram as médias mais altas para os aspectos afetivos, tanto positivo quanto negativo, demonstrando a intensidade do efeito da música ao vivo.

Vale destacar que, no estudo 1, o grupo com música ao vivo avaliou o afeto negativo mais intensamente do que o grupo com ausência de música. Mas, no estudo 2, essa avaliação foi invertida. Esse resultado pode sugerir que novas pesquisas precisam ser feitas para um melhor entendimento do verdadeiro impacto da música ao vivo sobre os aspectos negativos.

As músicas que foram emitidas no supermercado tinham um ritmo lento para moderado, característico de músicas famosas da MPB, que são cantadas por músicos como: Djavan, Maria Gadú, Gilberto Gil, Marisa Monte, Cássia Eller, Caetano Veloso, Vanessa da Mata, Chico Buarque, entre outros. O grupo experimento apresentou uma maior propensão a permanecer no local, levando a acreditar que a música tenha ajudado nessa avaliação. O estudo de Milliman (1986) contribui com essa afirmação porque verificou que as variações de ritmo da música podem significativamente afetar as compras, o tempo de permanência e outras variáveis.

Ainda corroborando o parágrafo anterior, o estudo de Demoulin (2011) traz contribuições quanto ao tipo de música que será tocada no ambiente de varejo, pois, para esse autor, a harmonia da música leva à baixa ativação, o que gera prazer alto. O prazer induzido pela harmonia da música aumenta a avaliação da qualidade do ambiente e da qualidade do serviço, o que afeta positivamente a intenção de retorno dos clientes. Como o perfil das músicas e a performance do cantor pode gerar baixa ativação, as respostas dos indivíduos do grupo experimento podem ter sido influenciadas por esta situação de prazer alto induzido.

A música ao vivo foi importante mesmo para o ambiente de varejo de um estabelecimento não projetado para experiências hedônicas. Os supermercados ficam localizados em bairros de classe média. O público que o frequenta, geralmente, busca preços baixos, e esta é a estratégia de posicionamento do grupo empresarial para competir no mercado. Porém, percebe-se que os estabelecimentos não investem em uma estrutura física diferenciada, disponibilizando para o cliente um local operacional, sem muitos requintes. $\mathrm{O}$ resultado encontrado nesta pesquisa vai ao encontro do indicado na teoria, e a novidade aqui, além da aplicação da música ao vivo, está também no fato de o ambiente investigado não ser sofisticado ou trabalhado para oferta de experiências memoráveis, indicando que também neste tipo de ambiente, a música ao vivo oferece reações intensas para os clientes, e não é, necessariamente, algo caro ou de difícil operacionalização pelo varejista.

Toda pesquisa apresenta limitações, em especial nas ciências sociais em que se lida com indivíduos complexos e a realidade é socialmente construída. Desse modo, na presente pesquisa, com uma perspectiva positivista, as seguintes limitações merecem destaque: (a) o ambiente real de varejo pode não ter isolado o efeito de outras variáveis, que não somente a música, na avaliação do respondente sobre os itens mensurados no questionário e (b) todo instrumento de mensuração apresenta erros por omissão de variáveis relevantes que compõem um determinado construto, o que pode ter ocorrido aqui.

Além das limitações já descritas, cabe destacar as limitações decorrentes do common method bias em pesquisas comportamentais. De acordo com Podsakoff, Mackenzie, Lee e Podsakoff (2003), a correlação entre dois construtos, pautada em considerações teóricas, pode apresentar um efeito 
sistemático entre as medidas se os construtos tiverem medidas que compartilham métodos comuns. As medidas desta presente pesquisa compartilham do mesmo método de coleta e análise de dados, por isso os resultados devem ser considerados com cautela.

Algumas recomendações para futuras pesquisas são: (a) mensurar o efeito da música em lojas de varejo onde este elemento seja parte da experiência de consumo, planejada para ter destaque no ambiente e na identidade da loja; (b) realizar estudos de inspiração fenomenológica buscando identificar o significado da música para os consumidores no ponto de venda e a relação com o processo de compra; (c) investigar junto a pessoas com deficiência visual o papel da música no ponto de venda: se hedônico ou racional, e quais as implicações da presença de música para estes consumidores.

\section{Referências}

Andersson, P. K., Kristensson, P., Wästlund, E., \& Gustafsson, A. (2012). Let the music play or not: the influence of background music on consumer behavior. Journal of Retailing and Consumer Services, 19(6), 553-560.

Areni, C. S. (2003). Exploring managers' implicit theories of atmospheric music: comparing academic analysis to industry insight. Journal of Services Marketing, 17(2), 161-184.

Associação Brasileira de Supermercados. (2013, setembro 10). Estrangeiros dominam setor de supermercado. Recuperado em 10 dezembro, 2013, de www.abras.com.br/clipping.php?area $=20 \&$ clipping $=40687$

Bailey, L. M. (1983). The effects of live music versus tape-recorded music on hospitalized cancer patients. Music Therapy, 3(1), 17-28. doi: 10.1093/mt/3.1.17

Bailey, N., \& Areni, C. S. (2006). When a few minutes sounds like a lifetime: does atmospheric music contract perceived time? Journal of Retailing, 82(3), 189-202. doi: 10.1016/j.jretai.2006.05.003

Baker, J., Levy, M., \& Grewall, D. (1992). An experimental approach to marketing retail store environment decisions. Journal of Retailing, 68(4), 445-460.

Bartók, B. (1976). Mechanical music. In B. Suchoff (Ed.), Béla bartók essas (pp. 289-98). New York: St. Martin's Press.

Baumol, W. J., \& Bowen, W. G. (1966). Performing arts: the economic dilemma. New York: Twentieth Century Fund.

Bitner, M. J. (1992). Servicescapes: the impact of physical surroundings on customers and employees. Journal of Marketing, 56(2), 57-71. doi: 10.2307/1252042

Bruner, G. C., II (1990). Music, mood, and marketing. Journal of Marketing, 54(4), 94-104. doi: $10.2307 / 1251762$

Chebat, J.-C., Chebat, C. G., \& Vaillant, D. (2001). Environmental background music and in-store selling. Journal of Business Research, 54(2), 115-123. doi: 10.1016/S0148-2963(99)00089-2

Cohen, J. B., Pham, M. T., \& Andrade, E. B. (2008). The nature and role of affect in consumer behavior. In C. P. Hautvedt, P. M. Herr, \& F. Kardes (Eds.), Handbook of consumer psychology (pp. 297348). New York: Lawrence \& Erlbaum.

Cox, K. (1964). The responsiveness of food sales to shelf space changes in supermarkets. Journal of Marketing Research, 1(2), 63-67. doi: 10.2307/3149924 
Crowley, A. E. (1993). The two-dimensional impact of color on shopping. Marketing Letters, 4(1), 5969. doi: 10.1007/BF00994188

Demoulin, N. T. M. (2011). Music congruency in a service setting: the mediating role of emotional and cognitive responses. Journal of Retailing and Consumer Services, 18(1), 10-18. doi: 10.1016/j.jretconser.2010.08.007

DeNora, T., \& Belcher, S. (2000). When you're trying something on you picture yourself in a place where they are playing this kind of music': musically sponsored agency in the British clothing retail sector. The Sociological Review, 48(1), 80-101. doi: 10.1111/1467-954X.00204

Donovan, R., \& Rossiter, J. R. (1982). Store atmosphere: an environmental psychological approach. Journal of Retailing, 58(1), 34-57.

Fischer, J. D. (1974). Situation-specific variables as determinants of perceived environmental aesthetic quality and perceived crowdedness. Journal of Research in Personality, 8(2), 177-188. doi: 10.1016/0092-6566(74)90019-1

Frederickson, J. (1989). Technology and music performance in the age of mechanical reproduction. International Review of the Aesthetics and Sociology of Music, 20(2), 193-220. doi: $10.2307 / 836729$

Frith, S. (2013). Live music exchange. Popular Music, 32(2), 297-301. doi: $10.1017 / \mathrm{S} 0261143013000068$

Garlin, F. V., \& Owen, K. (2006). Setting the tone with the tune: a meta-analytic review of the effects of background music in retail settings. Journal of Business Research, 59(6), 755-764. doi: 10.1016/j.jbusres.2006.01.013

Götell, E., Brown, S., \& Ekman, S. L. (2009). The influence of caregiver singing and background music on vocally expressed emotions and moods in dementia care: a qualitative analysis. International Journal of Nursing Studies, 46(4), 422-430. doi: 10.1016/j.ijnurstu.2007.11.001

Hayes, A. F. (2013). Introduction to mediation, moderation, and conditional process analysis. New York: The Guidford Press.

Herrington, J. D., \& Capella, L. M. (1994). Practical applications of music in service settings. Journal of Services Marketing, 8(3), 50-65. doi: 10.1108/08876049410065615

Herschmann, M. (2008, setembro). Revalorização da música ao vivo em um contexto de crise da indústria fonográfica. Anais do Congresso Brasileiro de Ciências da Comunicação, Natal, RN, Brasil, 31.

Iazzetta, F. (1997). A música, o corpo e as máquinas. Revista Opus, 4(4), 27-44.

Jain, R., \& Bagdare, S. (2011). Music and consumption experience: a review. International Journal of Retail \& Distribution Management, 39(4), 289-302. doi: 10.1108/09590551111117554

Kaltcheva, V. D., \& Weitz, B. A. (2006). When should a retailer create an exciting store environment? Journal of Marketing, 70(1), 107-118. doi: 10.1509/jmkg.2006.70.1.107

Kellaris, J. J., \& Kent, R. J. (1993). An exploratory investigation responses elicited by music varying in tempo, tonality, and texture. Journal of Consumer Psychology, 2(4), 381-401. doi: 10.1016/S1057-7408(08)80068-X

Kellaris, J. J., \& Rice, R. C. (1993). The influence of tempo, loudness, and gender of listener on responses to music. Psychology \& Marketing, 10(1), 15-29. doi: 10.1002/mar.4220100103 
Kotler, P. (1973). Atmospherics as a marketing tool. Journal of Retailing, 49(3), 48-64.

Larsen, J. T., McGraw, P. A., \& Cacioppo, J. T. (2001). Can people feel happy and sad at the same time? Journal of Personality and Social Psychology, 81(4), 684-696. doi: 10.1037/0022-3514.81.4.684

Lee, D., Henderson, A., \& Shum, D. (2004). The effect of music on preprocedure anxiety in Hong Kong Chinese day patients. Journal of Clinical Nursing, 13(3), 297-303. doi: 10.1046/j.13652702.2003.00888.x

Leichtentritt, H. (1934). Mechanical music on old times. The Musical Quartely, 20(1), 15-26.

Matilla, A. S., \& Wirtz, J. (2001). Congruency of scent and music as a driver of in-store evaluations and behavior. Journal of Retailing, 77(2), 273-289. doi: 10.1016/S0022-4359(01)00042-2

McGoldrick, P. J., \& Pieros, C. P. (1998). Atmospherics, pleasure and arousal: the influence of response moderators. Journal of Marketing Management, 14(1/3), 173-197. doi: $10.1362 / 026725798784959372$

Mehrabian, A., \& Russell, J. A. (1974). An approach to environmental psychology. Cambridge, MA: MIT Press.

Milliman, R. E. (1986). The influence of background music on the behavior of restaurant patrons. Journal of Consumer Research, 13(2), 286-289. doi: doi.org/10.1086/209068

Mowen, J. C., \& Minor, M. S. (2003). Comportamento do consumidor. São Paulo: Prentice Hall.

Nguyen T. T. M., Nguyen, T. D., \& Barrett, N. J. (2007). Hedonic shopping motivations, supermarket attributes, and shopper loyalty in transitional markets: evidence from Vietnam. Asia Pacific Journal of Marketing and Logistics, 19(3), 227-239. doi: 10.1108/13555850710772914

North, A. C., Hargreaves, D. J., \& McKendrick, J. (1999). The influence of in-store music on wine selections. Journal of Applied Psychology, 84(2), 271-276. doi: 10.1037/0021-9010.84.2.271

Podsakoff, P. M., Mackenzie, S. B., Lee, J.-Y., \& Podsakoff, N. P. (2003). Common method biases in behavioral research: a critical review of the literature and recommended remedies. Journal of Applied Psychology, 88(5), 879-903. doi: 10.1037/0021-9010.88.5.879

Pride, W. M., \& Ferrell, O. C. (2010). Marketing. Mason, OH: South-Westhern Cengage Learning.

Sherratt, K., Thornton, A., \& Hatton, C. (2004). Music interventions for people with dementia: a review of the literature. Aging \& Mental Health, 8(1), 3-12. doi: 10.1080/13607860310001613275

Smith, P. C., \& Curnow, R. (1966). "Arousal hypothesis" and the effects of music on purchasing behavior. Journal of Applied Psychology, 50(3), 255-256. doi: 10.1037/h0023326

Sousa, J. P. (1906). The menace of mechanical music. Appleton's Maganize, 8, 278-284.

Spangenberg, E. R., Crowley, A. E., \& Henderson, P. (1996). Improving the store environment: do olfactory cues affect evaluations and behaviours? Journal of Marketing, 60(2), 67-80. doi: $10.2307 / 1251931$

Spangenberg, E. R., Grohmann, B., \& Sprott, D. E. (2005). It's beginning to smell (and sound) a lot like Christmas: the interactive effects of ambient scent and music in a retail setting. Journal of Business Research, 58(11), 1583-1589. doi: 10.1016/j.jbusres.2004.09.005

Taylor, T. D. (2007). The commodification of music at the dawn of the era of "mechanical music". Ethnomusicology, 51(2), 281-305. 
Vida, I., Obadia, C., \& Kunz, M. (2007). The effects of background music on consumer responses in a high-end supermarket. The International Review of Retail, Distribution and Consumer Research. 17(5), 469-482. doi: 10.1080/09593960701631532

Vleuten, M. van der, Visser, A., \& Meeuwesen, L. (2012). The contribution of intimate live music performances to the quality of life for persons with dementia. Patient Education and Counseling, 89(3), 484-488. doi: 10.1016/j.pec.2012.05.012

Watson, D., Clark, L. A., \& Tellegen, A. (1988). Development and validation of brief measures of positive and negative affect: the PANAS scale. Journal of Personality and Social Psychology, 54(6), 1063-1070. doi: 10.1037/0022-3514.54.6.1063

Yalch, R. F., \& Spangenberg, E. R. (2000). The effects of music in a retail setting on real and perceived shopping times. Journal of Business Research, 49(2), 139-147. doi: 10.1016/S01482963(99)00003-X

Yim, M. Y.-C., Yoo, S.-C., Sauer, P. L., \& Seo, J. H. (2014). Hedonic shopping motivation and coshopper influence on utilitarian grocery shopping in superstores. Journal of the Academy of Marketing Science, 42(5), 528-544. doi: 10.1007/s11747-013-0357-2

\section{Dados dos Autores}

Marconi Freitas da Costa

Av. Prof. Luciano Gualberto, 908, 05508-010, São Paulo, SP, Brasil. E-mail: marconi_costa@ hotmail.com

Salomão Alencar de Farias

Av. Prof. Moraes Rego, 1235, Cidade Universitária, 50740-580, Recife, PE, Brasil. E-mail: saf@ufpe.br 